\title{
Evaluation and Comparison of Sustainability Performance and Visual Preference of Residential Landscape Elements
}

\author{
Xiaolin Huang ${ }^{1}$ and Julieta Trevino Sherk ${ }^{2,3}$
}

ADDITIONAL INDEX WORDs. client education, landscape elements, visual satisfaction

SUMmary. A study was conducted to compare sustainability performance (SP) and visual preference of landscape elements in six professionally designed landscapes. The sites chosen for study provided a range of low to high emphasis on sustainable landscape design. Landscape elements in each site were evaluated for two attributes: SP and visual preference. Sustainability performance was evaluated using the Sustainable Sites Initiative (SSI) scoring system. Visual preferences for landscape elements were assembled by surveying three populations of volunteers: landscape design professionals, landscape design students, and nondesigners (potential residential clients). Few significant differences were observed among the visual preference responses of participant groups. In the few differences noted, we found that the more knowledgeable participants were about landscape element's ability to improve the environment, the more likely they were to rate them as visually preferred. Average values for SP and visual preference were negatively correlated. However, many individual landscape elements were rated highly in both SP and visual preference. These results suggest it is possible to design landscapes with both highly sustainable elements that are also highly visually preferred.

$\mathrm{H}$ omeowners tend to view their outdoor residential environments as serving multiple functions: a place to observe nature, to socialize, and to provide beauty and recreation (Blaine et al., 2012). According to a nationwide survey of 2253 participants funded by the American Society of Landscape Architects (ASLA) in 2008, few homeowners understand the value or know how to accomplish sustainable strategies in their home landscapes (ASLA, 2008). Residential clients are largely unaware of the ability of their landscapes to reduce home energy costs, of the potential benefit to the environment, or even of the possibility of incorporating productive landscapes in their outdoor spaces. At the same time, once informed, homeowners value landscape elements that perform sustainably and would be willing to pay an additional amount for the inclusion of sustainable features in their home landscapes (Bowman et al., 2012).

In urban ecosystems, humans affect ecological patterns and processes

Department of Horticultural Science, North Carolina State University, 166 Kilgore Hall, Campus Box 7609, Raleigh, NC 27695-7609

${ }^{1}$ Former Graduate Teaching Assistant

${ }^{2}$ Assistant Professor

${ }^{3}$ Corresponding author. E-mail: jtsherk@ncsu.edu. through the design, creation, and management of unique habitats (Byrne, 2005). Consequently, sustainable development is becoming a dominating principle in planning a new and compact format of city residential areas (Zavadskas et al., 2007). Sustainability in land practices in this study is defined as "enabling natural and built systems to work together to meet the needs of the present without compromising the ability of future generations to meet their own needs." This is the definition of sustainable development first proposed in a 1987 report prepared by the United Nations World Commission on Environment and Development, led by Gro Harlem Brundtland, a Prime Minister of Norway, and is referred to as the Brundtland Report (World Commission on Environment and Development, 1987). This concept of sustainable development, one that can be sustained in the long term without damaging the environment, has become the watchword of environmental policy in the $1990 \mathrm{~s}$ (Goodchild, 1994).

The SSI is an interdisciplinary effort by the partnership of ASLA (Washington, DC), the Lady Bird Johnson Wildflower Center (University of Texas, Austin), and the U.S. Botanic Garden (Washington, DC) to create voluntary national guidelines and performance benchmarks for sustainable land design and for construction and maintenance practices. This valuation system is in a pilot phase yet represents a standard that has been well documented in the literature and applied in many pilot projects nationwide and internationally in Canada, Iceland, and Spain (ASLA, 2009b). Sustainable residential design can be categorized into the following SSI themes: water, vegetation, energy, human health, and construction materials.

When valuing aesthetic perceptions of the landscape through visual preference studies, there is a wide range of possible reactions. According to a study by Kaplan (1985), there are three implications that have bearing on the strengths and shortcomings of assessing aesthetics of landscapes through visual preference techniques: 1) "the arrangement of elements in space is a central factor in human environmental preference"; 2) "landscape is preferred when wayfinding is more likely, when there are elements that invite one to go deeper into the scene, and when landscape is legible"; and 3 ) "environmental preference does not constitute an adequate substitute for input from the individual impacted by particular decision or project" (Kaplan, 1985).

Sustainability in residential landscape design affects the environment, energy conservation, and society/culture. Sustainability performance and visual preference can be analyzed to provide guidance that could improve the way designers make decisions about implementing sustainable design methods in an aesthetic way. Yet, little research is published on this subject. Landscape categories comprising water, plantings, gathering, and circulation areas can be described and quantified to reveal information that designers can apply in their work. Therefore, the objective of this study was to review the relationship between SP and visual preference, and to compare visual preference ratings among three populations; professional designers, design students, and nondesigners.

\section{Materials and methods}

Site SELECTION AND SP sCORING. Six professionally designed residential landscape sites in the Research Triangle area of North Carolina 


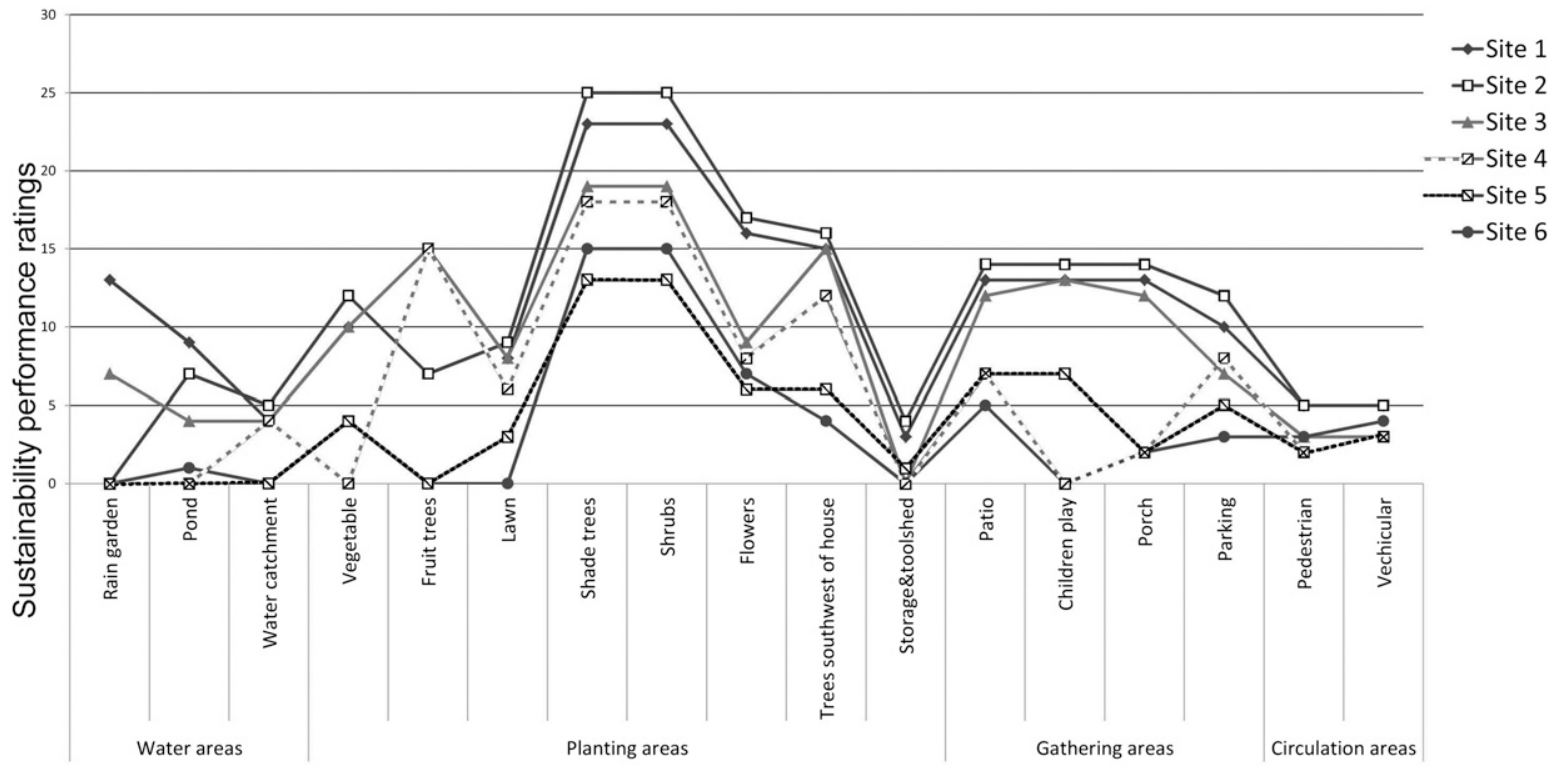

Fig. 1. Comparison of sustainable performance ratings totals using the Sustainable Sites Initiative (SSI) scoring system for 16 landscape elements organized in to four area categories: water, planting, gathering, and circulation. The six lines represent the six residential landscape study sites located in the Research Triangle area of North Carolina.

Table 1. Sustainable Site Initiative (SSI) performance benchmark credit criteria and corresponding ratings organized into the water, gathering, planting, and circulation area categories for six residential landscape study sites in the Research Triangle area of North Carolina.

\begin{tabular}{|c|c|c|c|c|c|c|c|}
\hline \multirow{2}{*}{ Area category $^{z}$} & \multirow[b]{2}{*}{ SSI credit criterion ${ }^{y}$} & \multicolumn{6}{|c|}{ SSI rating ${ }^{\mathrm{x}}$} \\
\hline & & Site 1 & Site 2 & Site 3 & Site 4 & Site 5 & Site 6 \\
\hline \multirow[t]{2}{*}{ Water } & 3.7 Rainwater /stormwater features & 17 & 8 & 10 & 0 & NA & NA \\
\hline & Water sub-total $=58$ & 26 & 12 & 15 & 4 & 0 & 1 \\
\hline \multirow[t]{5}{*}{ Planting } & 3.2 Reduce potable water use for landscape irrigation & 28 & 26 & 21 & 19 & 5 & NA \\
\hline & 4.11 Use vegetation to minimize building cooling requirements & 21 & 23 & 18 & 13 & 11 & 10 \\
\hline & 5.9 Support sustainable practices in plant production & 8 & 8 & 9 & 8 & 6 & 5 \\
\hline & $\begin{array}{l}\text { 6.7 Provide views of vegetation and quiet outdoor spaces } \\
\text { for mental restoration }\end{array}$ & 20 & 19 & 17 & 15 & 10 & 10 \\
\hline & 8.3 Recycle organic matter & 3 & 3 & 3 & 0 & 0 & NA \\
\hline \multirow{6}{*}{ Gathering } & 5.5 Use recycled content materials & 7 & 7 & 7 & 2 & 1 & 1 \\
\hline & 5.6 Use certified wood & 8 & 8 & 8 & 2 & 4 & 2 \\
\hline & 5.7 Use regional materials & 11 & 12 & 10 & 2 & 4 & 2 \\
\hline & 6.6 Provide opportunities for outdoor physical activity & 6 & 6 & 4 & 6 & 4 & 3 \\
\hline & 6.8 Provide outdoor spaces for social interactions & 8 & 8 & 5 & 6 & 4 & 2 \\
\hline & Gathering sub-total $=195$ & 49 & 54 & 44 & 17 & 21 & 10 \\
\hline \multirow[t]{3}{*}{ Circulation } & 6.5 Provide for optimum site accessibility, safety, and way finding & 6 & 6 & 3 & 2 & 2 & 3 \\
\hline & 6.9 Reduce light pollution & 4 & 4 & 3 & 3 & 3 & 4 \\
\hline & Circulation sub-total $=43$ & 10 & 10 & 6 & 5 & 5 & 7 \\
\hline
\end{tabular}

${ }^{\mathrm{z}}$ Landscape elements are organized into four area categories: water, planting, gathering, and circulation areas.

ySSI credit category numbers and descriptions applicable to residential landscapes (ASLA, 2009a).

${ }^{x}$ Ratings are the SSI category points totals assigned to each site. NA indicates that the particular SSI category was not present on the site and is therefore not applicable. 


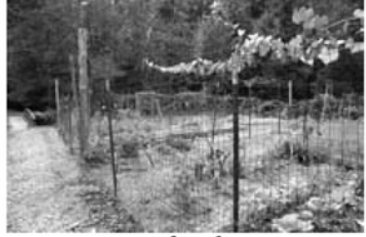

site 1

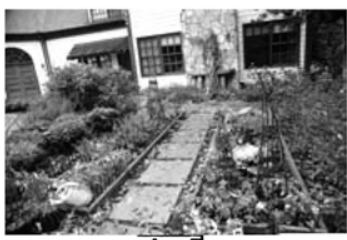

site 5

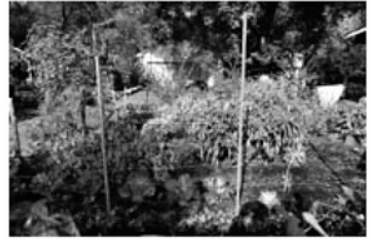

site 2

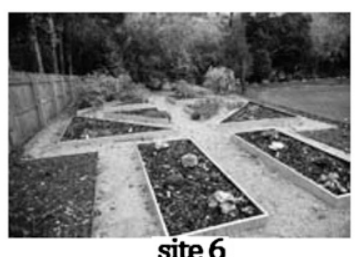

Fig. 2. An example of the types of images included in a visual preference survey evaluated by participants in a residential landscape study of six sites in the Research Triangle area of North Carolina. Pictured here are the vegetable garden images from sites $1,2,3,5$, and 6 , which were used in the visual preference assessment. were selected for study. The study sites, designed by four different registered landscape architects, were all about 0.3 acres $(0.12$ ha) in size, 5 to 10 years in age, and were in middleclass suburban neighborhoods. The sites were selected to represent a range of emphasis on sustainable design elements ranging from sites that were designed with very little focus on sustainable elements to sites in which sustainability was a major focus. To confirm and document the range of SP each site was scored using the SSI guidelines (ASLA, 2009a). Guidelines and performance benchmark rating credits outlined by the SSI were reviewed, and only those relevant to residential landscape spaces were chosen for the evaluation. These were divided into four area categories:

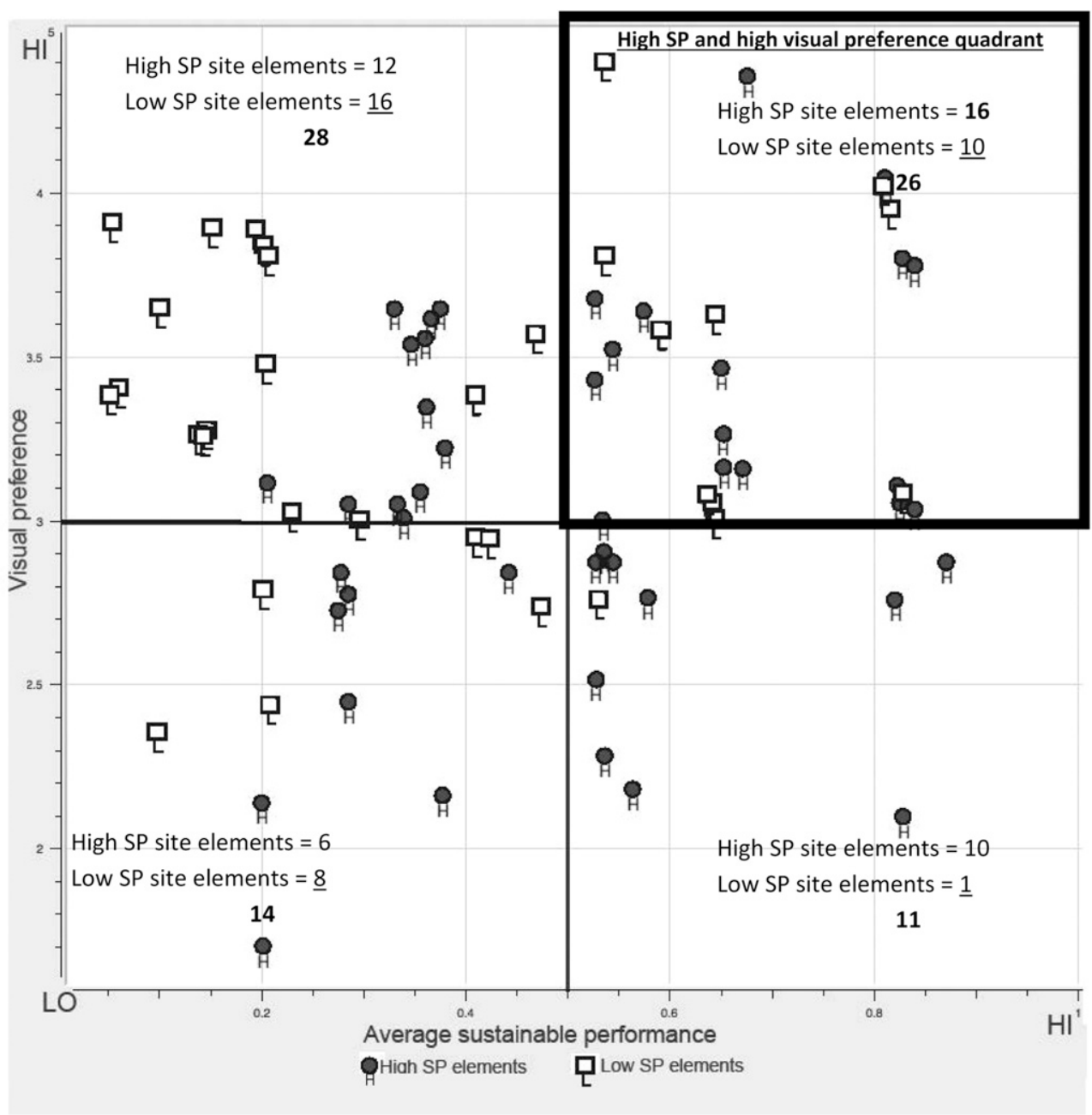

Fig. 3. Cluster graph comparing sustainable performance ratings with visual preference ratings. Sustainable performance ratings, using the Sustainable Sites Initiative (SSI) scoring system, were normalized to a 0 to 1 scale for this analysis. Visual preference ratings for each landscape element, using a Likert scale $(5=$ strongly like, $1=$ strongly dislike $)$, were averaged across all survey responses for each site. Points on graph represent visual preference and sustainable performance values for each of the 16 landscape elements from six study sites in the Research Triangle area of North Carolina. Elements from three lower sustainable performance sites are designated with an " $L$ "; elements from three higher sustainable performance sites are designated with an " $H$ ". 
water, planting, gathering, and circulation areas. Sixteen evaluated landscape elements were identified and organized into the four area categories (Fig. 1). For clarity, landscape elements will be shown in quotes throughout the text. Using the SSI method, scores were coded depending on the presence and quality of the landscape element relative to the criteria set forth in the SSI rating scales. For example, the "pedestrian" and "vehicular" elements belong in the circulation areas category. In this category, only credits 6.5 and 6.9 of the SSI credit system were used for the evaluation (Table 1). To insure consistency, one researcher scored all the sites.

VISUAL PREFERENCE SCORING. To reveal the difference in visual preference, images were taken of the 16 landscape elements at each site and the scenic beauty estimation (SBE) approach (Daniel and Schroeder, 1979) was used to evaluate visual preferences. Scenic beauty estimation is a system for quantitatively indexing the aesthetic quality of a landscape based upon personal visual preference judgments. To apply the SBE method, all images from each site were rated by participants using a Likert five-point scale where $5=$ strongly like, $4=$ like, 3 = neutral, 2 = dislike, $1=$ strongly dislike (Likert, 1932). To facilitate visual comparison between landscape elements from the different residences, images of the spaces in each residence were taken from similar points of view and at a similar scale as represented in the images of "vegetable" gardens taken from sites 1, 2, $3,4,5$, and 6 (Fig. 2). Some sites did not include all landscape element classifications and therefore were not evaluated for those elements. A list of local registered landscape architects, North Carolina State University landscape architecture students, and randomly selected nondesigners were asked to participate in the survey. The 36 respondents consisted of 8 registered landscape architects, 10 landscape architecture students, and 18 nondesigners (potential residential clients). All participants received an identical introduction and instructions for taking the survey and were asked to rank each image using an online evaluation form consisting of a series of images for each element arranged in the appropriate area categories. Online survey results were subjected to analysis of variance using SAS (version 9; SAS Institute, Cary, NC). Differences in responses between the three participant populations: landscape design professionals, landscape architecture students, and nondesigners, were analyzed using pairwise comparisons.

Comparison OF SP AND VISUAL PREFERENCE. Based on the assessments of the two methods used to evaluate the sites, correlation comparisons between the SP and visual preference ratings were conducted. Correlation coefficient was calculated and scores were compared in a scatterplot using Orange, a data mining software suite featuring data analysis and visualization (Demšar et al., 2004) (Fig. 3).

\section{Results}

Sustainability evaluation. Total SP scores of the six sites ranged from 63 to 198 , confirming that our sites represented a range of sustainability in the designs (Table 1 ). Based on the overall totals, the sites were ranked from 1 to 6 , representing greatest SP to least respectively. With relatively few exceptions, subtotals for SP for each of landscape element

Table 2. Probability values from paired comparisons of survey participant responses to visual preferences for 16 landscape elements organized into four area categories for six residential landscape study sites in the Research Triangle area of North Carolina.

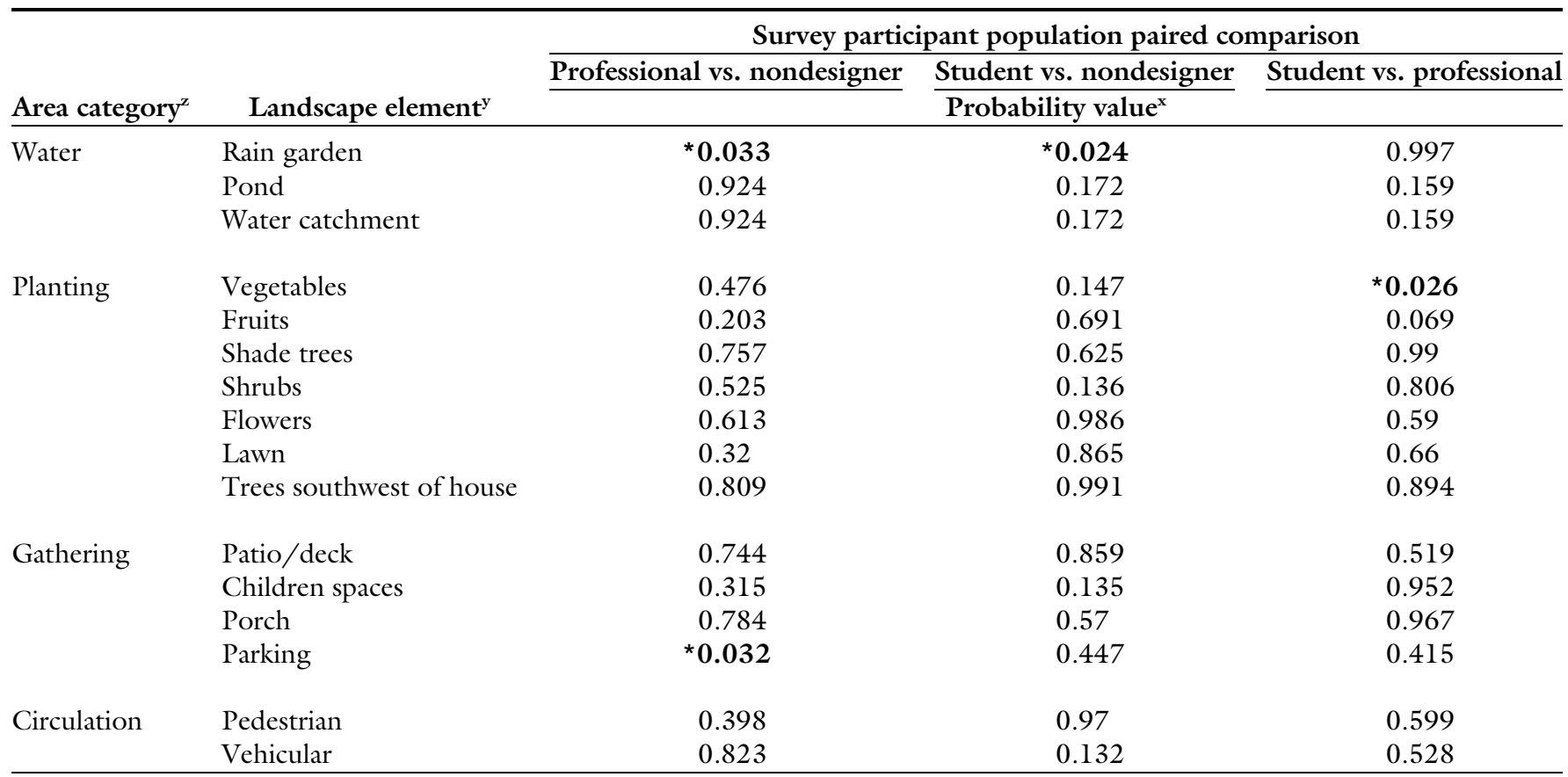

${ }^{\mathrm{z}}$ Landscape elements evaluated are organized into four area categories: water, planting, gathering, and circulation areas.

y Sixteen evaluated landscape elements were identified and organized into the four area categories.

xProbability values associated with F-tests to compare average rating scores of landscape element by nondesigner, landscape design students, and landscape design professionals using a Likert scale $(1=$ strongly dislike, $5=$ strongly like). Comparisons with $P \leq 0.05$ are designated in boldface identified with asterisks. 
categories ranked the six sites in similar order (Table 1). The SSI scoring system places greater emphasis on planting areas category elements, consequently it is not surprising to find that planting areas category scores had the greatest contribution to the total SSI score for each of the six sites. Gathering areas category contributed the second greatest total points, followed by water areas, and circulation areas category (Table 1 ). In the SP scoring, "lawn," "storage shed," "pedestrian," and "vehicular" areas yield lower SP scores; whereas "shade trees," "shrubs," "vegetables," "flowers," "trees southwest of house," "patio," "porches," and "children's play" resulted in higher SP values. Among all categories evaluated, "shade trees" and "shrubs" produced the highest overall ratings (Fig. 1).

VIS U A L P R E F E R E N C E EVALUATION. Few differences in visual preferences were observed between the three groups of participants with significant differences $(P \leq 0.05)$, including "rain garden," "vegetables," and "parking" elements only (Table 2 ). For "rain garden," landscape design professionals and landscape architecture students gave higher visual preference ratings for the high SP site images than did nondesigners. For "vegetables," landscape design professionals gave higher visual preference ratings for the high SP site images than did landscape architecture students. For "parking," nondesigners gave higher visual preference ratings for the low SP site images than landscape design professionals.

The gathering areas category had the highest average of 3.39 followed by planting areas category landscape elements with an average of 3.24 (Table 3 ). The circulation areas category average was 3.20 , and water areas category elements had the lowest average of 2.89. Lack of elements in some sites affected overall visual satisfaction scores.

COMPARISON OF SP AND VISUAL PREFERENCE. Average visual performance scores for lower sustainability sites were $3.38,3.45$, and 3.30 , and the high sustainability sites had the lowest average visual performance scores of $3.09,3.05$, and 2.99 (Table 3 ). Visual preference ratings and total SP for the six study sites were negatively correlated $(r=-0.91)$ (Table 4$)$. When data for SP and visual preferences are used as $x$-axis and $y$-axis in a cluster diagram, the six sites clearly segregated into two distinct clusters (Fig. 4). Sites 1, 2, and 3 clustered together with higher SP values and lower visual perseverance scores. Sites 4,5 , and 6 clustered together with lower SP values and higher visual preference scores. These lower SP and higher SP designations were used to identify the sites in a cluster graph of landscape element SP and visual

Table 3. Visual preference ratings scored by survey participants for 16 landscape elements from six residential landscape study sites in the Research Triangle area of North Carolina. Visual preference and category scores were averaged for comparison.

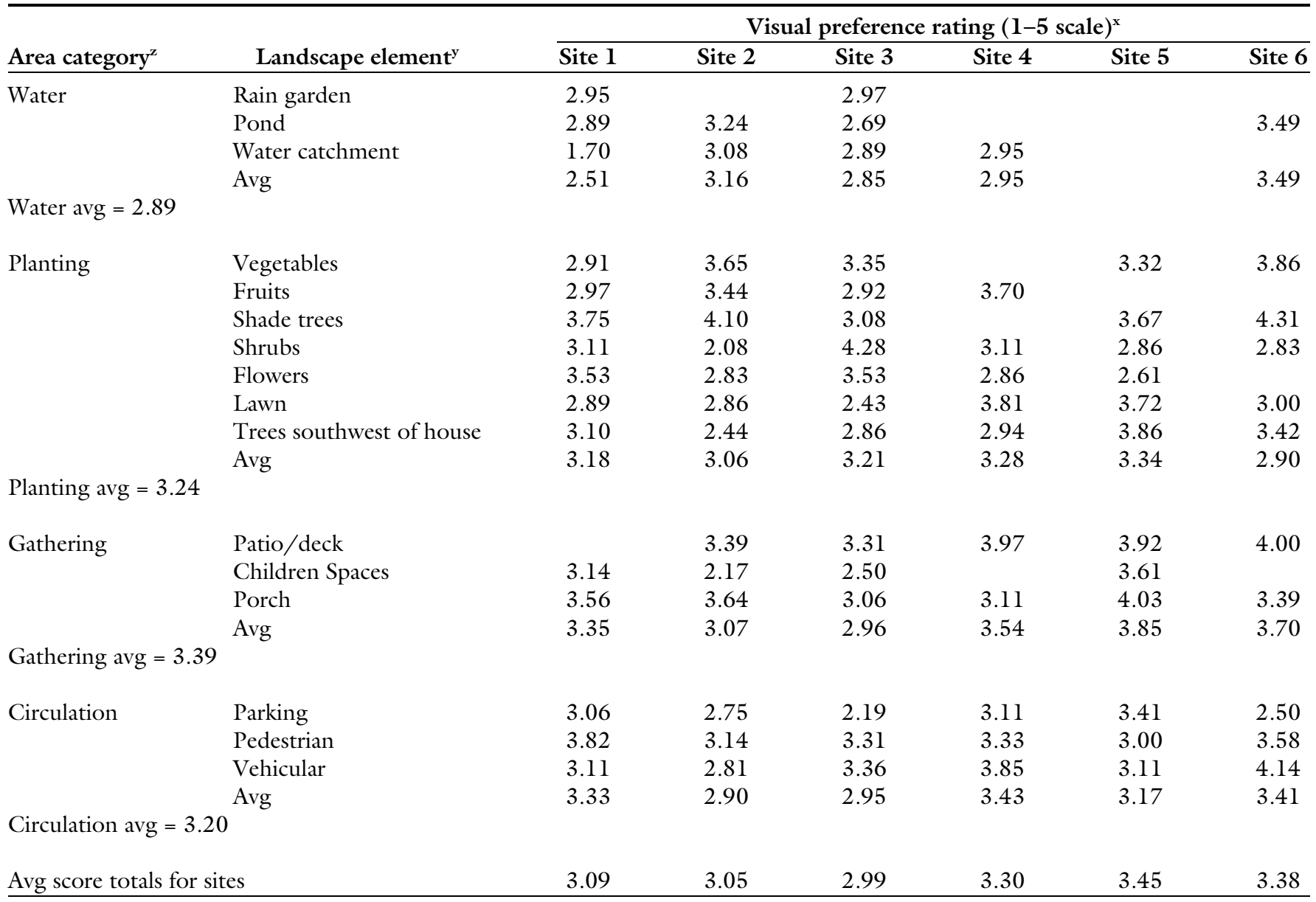

${ }^{z}$ Landscape elements evaluated are organized into four area categories: water, planting, gathering, and circulation areas.

ysixteen evaluated landscape elements were identified and organized into the four area categories.

${ }^{x}$ Visual preference rating using a Likert scale $(1=$ strongly dislike, $5=$ strongly like $)$ for each landscape element, averaged across all survey responses. 
Table 4. Comparison of sustainable performance rating totals and visual preference overall ratings averages of landscape elements for six residential landscape study sites in the Research Triangle area of North Carolina.

\begin{tabular}{lcc}
\hline Site & SSI rating total $^{\mathbf{z}}$ & Visual preference overall avg $(\mathbf{1}-\mathbf{5} \text { scale })^{\mathbf{y}}$ \\
\hline 1 & 198 & 3.09 \\
2 & 191 & 3.05 \\
3 & 160 & 2.99 \\
4 & 103 & 3.30 \\
5 & 72 & 3.45 \\
6 & 63 & 3.38 \\
& \multicolumn{2}{c}{ Correlation coefficient $r=-0.915$} \\
\hline
\end{tabular}

${ }^{2}$ Ratings were determined using the Sustainable Sites Initiative (SSI) category points totals assigned to each site (ASLA, 2009a).

'Visual preference rating using a Likert scale ( $\mathrm{l}=$ strongly dislike, $5=$ strongly like) for each landscape element, averaged across all survey responses for each site.

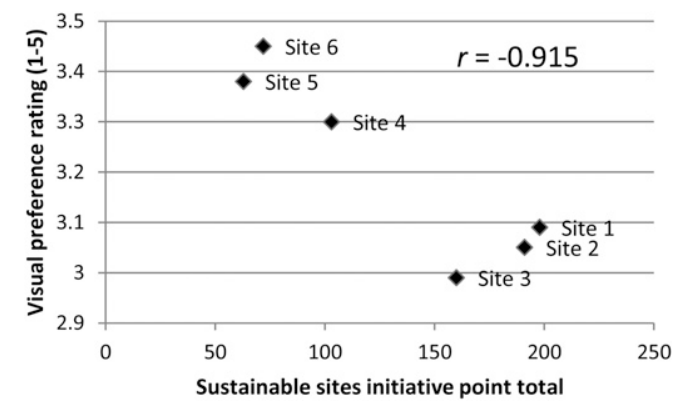

Fig. 4. Scatter plot comparison of sustainable performance rating totals, using the Sustainable Sites Initiative (SSI) scoring system and visual preference ratings using a Likert scale ( 5 = strongly like, $1=$ strongly dislike) from six residential landscape study sites in the Research Triangle area of North Carolina.

preference data (Fig. 3). Figure 3 is divided into four quadrants based on the midpoint of each dimension. Although landscape elements from low and high SP sites were seen in all four quadrants, landscape elements from low SP sites clustered in the high visual preference quadrants. Scores for individual elements in the high SP and high visual preference quadrant are highlighted in Fig. 3. Of the images that fell in the high SP and high visual preference rating quadrant, images of the high SP elements (16) dominated with only (10) from the low SP sites, suggesting that images from highly sustainable sites can also be highly visually preferred (Fig. 3).

\section{Discussion}

The importance of plantings in sustainable landscape design is highlighted in our results. We found that planting areas provided the highest SP scores, especially in the "shade trees" and "shrubs" classifications (Fig. 1). This is consistent with in the Sustainable Cities Institute with this statement (National League of Cities, 2013):

"Trees help to improve air quality by mitigating air pollution; Trees help to reduce stormwater runoff and improve water quality; Trees help to reduce the ... heat island effect; ... trees help to reduce, and even eliminate, erosion; Trees shelter wildlife and promote biodiversity; Healthy ... forests contribute to the stabilization of watersheds."

Although we found limited statistical significance between the visual preference ratings from the three backgrounds of the participant populations, the "rain garden" and "vegetables" were rated higher by landscape architects than by landscape architecture students or nondesigners. This may imply that participants with greater knowledge of sustainable functions of landscape elements will be more likely to assign higher aesthetic rankings to those elements. Conversely, "parking" was given higher ratings by nondesigners than by landscape architects. These results agree with Kaplan (1985) who reported that ratings from participants with prior knowledge of landscape design will be quite different from those without expertise.

COMPARISON OF SP AND VISUAL PREFERENCE. Highly negative correlation between SP and visual preference tends to support the notion that highly sustainable sites would not be pleasing in appearance. At first glance, the data in Fig. 3 reinforces this observation. However, elements within the high SP and high visual preference quadrant are dominated by elements from highly rated SP sites, confirming high SP design elements can also receive high ratings in visual preferences.

In the SP ratings in the planting areas category, "lawn" yielded a lower SP score, and "vegetables," "flowers," and "trees southwest of house" rated higher for SP values. In addition, the "vegetables" score is not as great in low SP sites as in high-level SP sites suggesting the benefit of the inclusion of food production. Likewise, the water areas category scores were lower in the low SP sites, suggesting the benefit to environmental sustainability of implementing a water conserving strategy such as using captured rainwater or gray water to reduce water waste and conserve sources of potable water (ASLA, 2009b). Additionally, the high SP ratings of the gathering area category suggest the importance of including them deliberately in the landscape. The landscape designs of the sites studied revealed that the approach of providing high visual impact by the use of plantings, water catchment, and gathering spaces can provide high sustainable ratings. Although the low sustainability sites had overall higher visual preferences scores, a closer look revealed that when the two evaluations were compared, there were many landscape elements rated highly for both.

Sheppard (2005) reported that visualization tools increase people's learning and therefore their more favorable perceptions of sustainable design (Sheppard, 2005). In addition, these data support Kaplan's (1985) assertion that prior knowledge affects one's visual preferences as seen in the results of this study; the more knowledgeable you are about landscape elements' ability to improve the environment, the more likely you are to rate highly sustainable 
landscape elements also highly visually preferable. Therefore, it may be useful to provide prospective clients an image survey of sustainable landscape elements to assess their personal visual preferences. Client survey results could help to guide the designer and may provide a learning experience for clients about the aesthetics of sustainable landscape elements. Further, the approach of assessing residential design for SP before and after developing a design may well help designers leverage high-performing sustainable elements in their designs. Our study indicates that these assessments should help the landscape designer to optimally address the stewardship of the environment while providing attractive landscapes that meet their clients' needs. This study is preliminary, lacks replication, and represents a small sample size. A more comprehensive evaluation is necessary to better define highly visually preferred landscape elements that also perform sustainably in the residential landscape.

\section{Literature cited}

American Society of Landscape Architects. 2008. Many save on utility bills indoors, but not with their yard, lawn, or garden, according to an American Society of Landscape Architects' survey: Lack of knowledge plays a key role; New report to address sustainable landscape design. 6 Jan. 2014. <http://www.asla.org/ newsreleasedetails.aspx?id=19890>.
American Society of Landscape Architects. 2009a. Rating system, guidelines and performance benchmarks. 16 Mar. 2014. <http://www.sustainablesites. org/report/Guidelines $\% 20$ and $\% 20$ Performance\%20Benchmarks_2009.pdf>.

American Society of Landscape Architects. 2009b. The case for sustainable landscapes. 23 Mar. 2014. <http:// www.sustainablesites.org/report/ The $\% 20$ Case $\% 20$ for $\% 20$ Sustainable $\% 20$ Landscapes_2009.pdf>.

Blaine, T.W., S. Clayton, P. Robbins, and P.S. Grewal. 2012. Homeowner attitudes and practices towards residential landscape management in Ohio, USA. Environ. Mgt. 50:257-271.

Bowman, T., J.C. Tyndall, J. Thompson, J. Kliebenstein, and J.P. Colletti. 2012. Multiple approaches to valuation of conservation design and low-impact development features in residential subdivisions. J. Environ. Mgt. 104:101-113.

Byrne, L.B. 2005. Of looks, laws and lawns: How human visual preferences influence landscape management, public policies and urban ecosystems. Proc. Urban Rural Interface Conf. p. 42-46.

Daniel, T.C. and H. Schroeder. 1979. The scenic beauty estimation model: Predicting perceived beauty of forest landscapes, p. 514-523. In: Proc. Our national landscapes: A conference on applied techniques for analysis and management of the visual resource. U.S. Dept Agr., For. Serv. Gen. Tech. Rpt., Pacific Southwest For. Range Expt. Sta. No. PSW-35.

Demšar, J., B. Zupan, G. Leban, and T. Curk. 2004. Orange: From experimental machine learning to interactive data mining, p. 537-539. In: J.F. Boulicaut, F. Esposito, F. Giannotti, and D. Pedreschi (eds.). Knowledge discovery in databases PKDD 2004. Springer Berlin, Heidelberg, Germany.

Goodchild, B. 1994. Housing design, urban form and sustainable development, reflection on the future residential landscape. Town Planning Rev. 65:143-157.

Kaplan, R. 1985. The analysis of perception via preference: A strategy for studying how the environment is experienced. Landscape Planning 12:161-176.

Likert, R. 1932. A technique for the measurement of attitudes. Arch. Psychol. 140:1-55.

National League of Cities, Sustainable Cities Institute 2013. Sustainable Cities Institute: Benefit of trees and the urban forest. 23 Mar. 2014 . <http:// www.sustainablecitiesinstitute.org/ topics/water-and-green-infrastructure/ urban-forestry>.

Sheppard, S.R.J. 2005. Landscape visualization and climate change: The potential for influencing perceptions and behavior. Environ. Sci. Policy 8:637-654.

World Commission on Environment and Development. 1987. Our common future: Report of the World Commission on Environment and Development. 28 Mar. 2014. <http://www.un-documents.net/ our-common-future.pdf $>$.

Zavadskas, E., M. Viteikiene, and J. Saparauskas. 2007. Sustainable development assessment of cities and their residential districts. Ekologija 53:49-54. 